\title{
Subjetividade e Comunidade de Investigação no fazer Filosofia com Crianças: uma perspectiva sócio-histórica
}

\author{
Valeska Zanello $\underline{(1)}$
}

RESUMO: O texto parte da própria experiência da autora no Projeto Filosofia na Escola da Universidade de Brasília e visa apresentar uma possibilidade de leitura das dinâmicas que acontecem na comunidade de investigação do fazer filosofia com crianças, desde uma compreensão sócio-histórica da subjetividade. O elo escolhido são os conceitos de subjetividade pessoal, subjetividade social e sentido subjetivo.

Este texto visa apresentar uma reflexão acerca de minha participação no Projeto Filosofia na Escola (filosofia com crianças) da Universidade de Brasilia, no ano de 1999. Tendo uma formação filosófica, mas também psicológica, devo sublinhar que a perspectiva adotada será a busca pelas luzes que a psicologia da subjetividade, desde uma abordagem sócio-histórica, nos poderia lançar acerca de uma compreensão dos modos de funcionamento da comunidade de investigação. Isto é, a necessidade de se compreender a comunidade de investigação não apenas como um grupo reunido em torno do pensar, mas configurando também uma subjetividade social a ser qualificada e trabalhada. Aponto aqui a possibilidade de uma contribuição específica que pode ser desenvolvida pelos profissionais ou estudantes de psicologia que trabalhem em projetos semelhantes.

Como farei uma apresentação da realização do projeto na escola que trabalhei, escolhi fazê-la entremeada com minhas próprias observações e análises. O projeto nasceu no ano de 1998, na Faculdade de Educação da UnB, com os professores Walter Kohan e Ana Míriam Wuensch, junto a escolas públicas do DF. O objetivo não era a aplicação do programa de Lipman, mas desenvolver um projeto criativo que se adequasse à realidade das crianças envolvidas. Cada escola recebeu um grupo de monitores composto por três alunos, pertencentes a três áreas diferentes: filosofia, pedagogia e psicologia. A experiência de implementação do projeto bem como as vicissitudes de seu desenvolvimento podem ser encontradas no livro $A$ Filosofia na Escola Pública (2).

Minha integração ao projeto se deu no ano de 1999, e minha equipe foi composta apenas por duas pessoas, eu - representando a filosofia e a psicologia, e outro monitor da pedagogia. A escola na qual trabalhei encontrava-se na periferia de Brasília, e nosso trabalho aí consistiu em 3 etapas que no final do processo ficaram bem claras (3): num primeiro momento, eu e o outro monitor preparávamos as aulas, levávamos para a reunião com os professores, discutíamos o planejamento e depois assistíamos as aulas proporcionadas pelos professores junto às crianças. Nesta primeira etapa, percebemos uma tendência enorme das aulas de filosofia tornarem-se moral e cívica, ou seja, a pouca implicação pessoal do professor na feitura das aulas, acabava por não instigar no mesmo uma problematização de 
suas próprias crenças, passando este a "aplicar"a aula de filosofia que havíamos planejado.

Isto nos levou a uma mudança no planejamento das próprias aulas. Nesta segunda etapa, a cada semana uma dupla de professores deveria planejar a aula e realizá-la com toda a equipe que estava participando do projeto. Isto é, ao invés de avaliarem as aulas desde fora, sem uma implicação pessoal, os professores formavam uma comunidade de investigação, sendo instigados a opinarem, argumentarem, e também a relativizarem e exporem suas crenças. Comecei a perceber desde aqui, o quanto o projeto mexia não apenas com o racional das pessoas envolvidas, mas com a subjetividade toda do professor. Neste sentido, eram comuns intensas discussões quando os assuntos trabalhados relacionavam-se a temas morais e éticos (por exemplo: o que é amor, casamento entre homossexuais, o que é violência, etc). As resistências e insistências em determinados pontos de vista, ainda que não fosse possível sustentar argumentos compatíveis, começaram a se mostrar não como irracionalidade, mas como algo da subjetividade pessoal tocada pela questão. Quanto mais o professor conseguia relativizar seu ponto de vista e aceitar os diferentes, mais conseguia proporcionar nas suas aulas de filosofia com crianças o clima propício para o filosofar, isto é, facilitar o diálogo sem impor uma finalização ou uma moral da história, permitindo $e$ incitando a diversidade de opiniões desde que bem argumentadas.

Antes de passarmos para a descrição da terceira fase, faz-se necessário uma pequena pausa para inserirmos aqui conceitos importantes na nossa análise. Tratase de definir ou esclarecer o que estamos chamando de subjetividade (pessoal e social, indicando algumas de suas implicações). A teoria que escolhemos é a de Fernando Rey, psicólogo cubano que estudou na EX-URSS junto a uma das alunas de Vygotsky. Segundo ele, o termo subjetividade é composto sobretudo de duas categorias, a saber: sujeito e personalidade.

O sujeito é definido como o indivíduo concreto, com características essenciais e permanentes de sua condição: é atual, interativo, consciente e volitivo; por fim, portador de personalidade (Gonzalez-Rey, 1997).

Já a personalidade constitui um complexo sistema de sentidos configurados por recursos psicológicos de diferente ordem (unidades psicológicas primárias, formações motivacionais, elementos funcionais, etc.). Este sistema constitui o conjunto de recursos subjetivos com os quais o sujeito opera na determinação de seus comportamentos nas múltiplas e diversas situações nas quais se encontra (Martinez, 1998). A personalidade para o autor não seria um sistema fechado, mas antes um sistema dinâmico, processual, com relações indiretas com o meio social $e$ cultural. Indiretas - destaco - pois a subjetividade individual se constrói não como internalização do social, mas como constituição subjetiva individual, o que ressalta seu caráter de mediação e não linearidade entre um âmbito e outro. Há, deste modo, a questão do sentido subjetivo que para o sujeito concreto adquire determinados fatos, situações, etc. sociais; sentido este mediado pela personalidade do mesmo (com seu caráter histórico). O processo de mediação vai muito além da consciência do sujeito e envolve a importante questão da emocionalidade, que se 
faz através da emergência do sentido subjetivo, sendo que este último nem sempre é necessariamente significado. $\mathrm{O}$ "sentido é o valor emocional 'irrepetible' de um conteúdo e (...) a significação é o valor que pode adquirir conjunturalmente esse conteúdo no processo de regulação do comportamento pelo sujeito" (GonzalezRey, 1995, p. 80). Isto é, o sentido toca não apenas a dimensão cognitiva, mas o modo mesmo de sentir o mundo ou os fatos, do sentir-se e do agir do próprio sujeito. Sendo assim, a personalidade, por sua relativa 'abertura', seria sempre um novo momento constitutivo em relação ao anterior, nunca uma extensão acumulativa, pois está estruturada em categorias de sentido subjetivo "irrepetibles" como o próprio autor destaca.

É aqui que começamos a vislumbrar em que pontos a dinâmica da comunidade de investigação mexia na subjetividade dos professores e também dos monitores e das crianças. Tratava-se não apenas de uma mudança cognitiva, mas afetiva também, já que a própria questão do sentido estava sendo tocada. Entre outras questões, por exemplo, destaco a própria mudança na noção de infância ou de criança como alguém imaturo e incapaz de pensar, para alguém curioso, questionador $e$ pensante. A fala de uma das professoras é aqui instigadora: "Não imaginava que pessoas comuns e crianças pudessem pensar filosoficamente...percebia a filosofia como sendo domínio de intelectuais e filósofos. Hoje penso que todos nós podemos pensar de forma filosófica...". Este novo sentido se fazia presente não apenas nas palavras da professora, mas na sua disposição de escuta e qualificação da fala e das questões das próprias crianças (disposição levada agora para outras disciplinas; isto é, foi tocada a sua própria disposição de ser professora e sua relação com as crianças).

Gonzalez-Rey aponta ainda uma imbricação necessária e fundamental da subjetividade pessoal com a subjetividade social, sendo esta última: "(...) o sistema de configurações (grupais ou individuais) que se articulam nos distintos níveis da vida social, implicando-se de forma diferenciada nas distintas instituições, grupos e formações de uma sociedade concreta. Estas formas tão dessemelhantes, guardam complexas relações entre si e com o sistema de determinantes de cada sociedade concreta, aspectos que devem ser integrados e explicados (...)" (Gonzalez-Rey, 1996, pp. 99-100). Isto é, a subjetividade social não seria a mera soma de subjetividades individuais ou ainda de intersubjetividades, mas algo novo, que integra outro nível qualitativo do fenômeno subjetivo, que seria o social (presente em grupos ou instituições sociais). A subjetividade social, assim como a pessoal, tem um caráter histórico, e portanto idiossincrático. Dito de outra maneira, e do modo que nos interessa aqui, cada comunidade de investigação formava uma subjetividade social específica, marcada por um clima afetivo, modos e formas de comunicação e distribuição da palavra, de aceitação da diferença, etc. passíveis de serem observados, pesquisados e trabalhados (4). Quando a subjetividade do professor era tocada (na subjetividade social da comunidade de investigação dos professores, na confrontação de uma de suas idéias ou crenças), através da reconfiguração de sentidos (ainda que sua opinião se mantivesse a mesma, por exemplo, era percebida como sendo apenas uma possibilidade de argumentação, mas não a verdade), facilitava-se também o acontecimento das aulas de filosofia com crianças. Isto é, quanto mais engajado pessoalmente (poderíamos dizer 
"personalmente", remetendo à idéia da personalidade, da subjetividade pessoal) estivesse o professor com a filosofia, mais facilmente conseguia adotar uma postura de facilitador na comunidade de investigação com as crianças. Por outro lado, quanto menos envolvido estivesse, no sentido de repensar e questionar suas próprias opiniões e crenças (quanto menor o engajamento e a mudança subjetiva), mais tratava a filosofia como matéria a ser "aplicada" ainda que numa metodologia diferente, qual seja, a própria comunidade de investigação.

Podemos relatar agora a terceira fase de nossa experiência. Nesta etapa, passamos a buscar os temas das aulas de filosofia nas próprias crianças, isto é, através de suas sugestões e questões, o que acabou por gerar uma implicação muito maior das mesmas na própria comunidade de investigação, ocorrendo uma problematização de seus mundos e realidades. Nesta fase, muitas crianças que quase sempre se mantinham caladas e até mesmo desmotivadas, passaram a se expressar, opinar e debater no diálogo. Acredito que os temas eram muito mais motivadores, pois faziam parte da vivência (Erleben) das próprias crianças, isto é, tocavam na importante questão da emocionalidade e do sentido subjetivo.

Podemos assim, resumidamente, dizer que houve um "descentramento" ou um "rescentramento" na realização do projeto nesta escola: dos monitores para os professores, e destes para as crianças. Tal dinâmica pode ocorrer devido à facilitação que a comunidade de investigação dos professores proporcionava a cada professor para realizar ou facilitar a comunidade de investigação com as crianças. Lendo este processo de outra ótica, poderíamos dizer que a subjetividade social da comunidade de investigação dos professores mexia na importante questão do sentido subjetivo (cognitivo, mas também do sentir) do professor; e que este engajamento pessoal, proporcionava a cada professor maior ou menor desenvoltura para facilitar as aulas de filosofia, influenciando assim a própria subjetividade social da comunidade de investigação com as crianças.

Para finalizar este relato breve, gostaria de ressaltar a riqueza que a interdisciplinaridade trouxe à realização do projeto e de deixar aqui indicada esta possibilidade de trabalho ou enriquecimento do fazer filosofia com crianças por parte dos estudantes ou profissionais de psicologia. Como metodologia sugiro a pesquisa-ação (5), isto é, a perspectiva segundo a qual pesquisa e intervenção não sejam separadas, mas antes sejam partes concomitantes do processo, sendo a pesquisa uma intervenção, e a própria intervenção, "objeto" de pesquisa. Trata-se de fornecer uma leitura diferente (que qualifique a questão do sentido, enquanto cognitivo e afetivo) dos processos dinâmicos da comunidade de investigação, bem como elaborar estratégias para trabalhar os aspectos idiossincráticos aí percebidos (6).

\section{Referência bibliográfica}

Barbier, R. A pesquisa-ação. Tradução de Lucie Didio, Faculdade de Educação/UnB a partir de La recherche-action. Paris: Economica, 1996 
Gonzalez-Rey, F. Comunicación, personalidad y desarrollo. Havana: Editorial Pueblo y Educación, 1995.

-------- Problemas epistemológicos de la psicologia. Havana: Editorial Academia, 1996.

Epistemología Cualitativa y subjetividad. Havana: Editorial Pueblo y Educación, 1997.

Kohan et all (Orgs.). Filosofia na Escola Pública. Vol. IV. Petrópolis: Vozes, 2000.

Loyola, V.M.Z. \& Porto, F.G. CEAG: A consolidação de uma nova proposta. In: KOHAN et all (orgs.). Filosofia na Escola Pública. Vol. IV. Petrópolis: Vozes, 2000, pp.149-179.

Loyola, V.M.Z. \& Teles, A.O. A Subjetividade Social na Escola. Brasília: Ed. Paralelo 15, 1999.

Martinez, A.M. "Que profesor necessitamos? Desafios para su formación". DOXA Revista Paulista de Psicologia e Educação, UNESP, Ano IV, Vol. 4, No.1, pp. 87117, jan/jun, 1998.

(1) Bacharelanda em Filosofia e doutoranda em Psicologia pela Universidade de Brasília. E-mail: valeskazanello@uol.com.br.

(2) Kohan et all (orgs.). Filosofia na Escola Pública. Vol. IV. Petrópolis: Vozes, 2000.

(3) A descrição detalhada da história do projeto nesta escola se encontra em Loyola, V.M.Z. \& Porto, F.G. CEAG: A consolidação de uma nova proposta. In: KOHAN et all (orgs.). Filosofia na Escola Pública. Vol. IV. Petrópolis: Vozes, 2000, pp.149-179.

(4) Realizamos uma pesquisa-ação deste tipo, ainda que em um outro contexto, em uma escola pública de Brasília. Tal experiência encontra-se descrita em $A$ Subjetividade Social na Escola. Brasília: Ed. Paralelo 15, 1999.

(5) Barbier, R. A pesquisa-ação. Tradução de Lucie Didio, Faculdade de Educação/UnB a partir de La recherche-action. Paris: Economica, 1996.

(6) Um exemplo de pesquisa-ação pode ser encontrado em meu livro já citado, $A$ Subjetividade Social na Escola. 